\title{
A REVIEW ON ACOUSTIC MONITORING OF DEBRIS FLOW
}

\author{
J. HÜBL ${ }^{1}$, A. SCHIMMEL ${ }^{1}$, A. KOGELNIG ${ }^{1}$, E. SURIÑACH ${ }^{2}$, I. VILAJOSANA ${ }^{2}$ \& B.W. MCARDELL ${ }^{3}$ \\ ${ }^{1}$ Institute of Mountain Risk Engineering, University of Natural Resources and Life Sciences BOKU, \\ Vienna, Austria. \\ ${ }^{2}$ Research Group on Avalanches, Departament de Geodinàmica i Geofisica, Universidad de Barcelona, Spain. \\ ${ }^{3}$ Swiss Federal Institute for Forest, Snow and Landscape Research WSL, Birmensdorf, Switzerland.
}

\begin{abstract}
Debris flows and debris floods are processes that occur in high alpine regions with consequences on infrastructure and settlements. Recently, several studies have been conducted by the authors using a new approach to gather knowledge about debris flows using a combination of two acoustic sensors: seismic sensors and infrasound microphones. Both sensors have been individually used in a number of previous studies. But the potential combination of infrasonic and seismic sensors for monitoring natural hazards, which could take advantage of the benefits of both sensor technologies and the possibility of using this setup for early warning, has not been evaluated to date. As a consequence, in this study the most important characteristics of acoustic signals from debris flows monitored at different locations in the Austrian and Swiss Alps are summarized and possible interfering signals are presented. An approach of using this acoustic signal for early warning will be introduced and evaluated. In addition, the data will be compared with other measurements, such as flow depth, interpretation, verification, and validation of the seismic and infrasonic data.

Keywords: Debris flow, early warning, infrasound, monitoring, seismic waves.
\end{abstract}

\section{INTRODUCTION}

This study presents a comprehensive summary of debris flows monitoring using a combination of two acoustic sensors: seismometers and infrasound microphones. Both sensors have been individually used previously. Various earlier studies on debris flows (e.g. [1-7]) have already shown that it is possible to detect and monitor these processes using the seismic signal analysis.

On the other hand, infrasound technology has been used recently for the development of automatic detection systems for snow avalanches and debris flows [8-11].

However, the potential combination of infrasonic and seismic sensors for monitoring debris flows, which could take advantage of the benefits of both sensor technologies and the possibility of using this setup for early warning, has not been evaluated to date. Both seismic and infrasonic signals are mechanical waves that are often generated by the same physical phenomena. In addition, the Earth's surface is not opaque to mechanical waves, either those propagating upward from within the Earth's solid interior or those propagating down from the atmosphere [12].

The following work summarizes the most important characteristics of infrasound and seismic signals of debris flows and debris floods and presents an approach of early warning by using a detection algorithm based on both signal types. For this, data of one debris flow (Lattenbach torrent, Austria) and one debris flood (Illgraben torrent, Switzerland) have been chosen, which can be considered as typical for the respective processes. 


\section{ANALYSES OF ACOUSTIC DATA}

\subsection{Lattenbach torrent (Austria)}

The Lattenbach torrent (catchment $5.3 \mathrm{~km}^{2}$ ) is an observation site for debris flows operated by the Institute of Mountain Risk Engineering (BOKU, Vienna) in cooperation with the Austrian Service for Torrent and Avalanche Control (WLV) [13]. For a detailed overview of the test site see [14-16].

\subsubsection{Acoustic data}

A debris flow event was recorded on 01.09.2008 in the Lattenbach torrent (catchment area $5.3 \mathrm{~km}^{2}$ ) (Fig. 1). The event had a duration of $867 \mathrm{~s}$ (defined as time with flow depth $>30 \mathrm{~cm}$ ), a peak discharge of $380 \mathrm{~m}^{3} / \mathrm{s}$, and a total volume of $14.000 \mathrm{~m}^{3}$ within this time. This event has been previously discussed in $[14,15]$ and is only shortly summarized for the purpose of this article. The data were collected using an infrasound microphone, a geophone, and two ultrasonic gauges (with an inter-distance of $47.2 \mathrm{~m}$ ). The infrasound sensor used at this site was the Gefell WME $960 \mathrm{H}$, which has a frequency range from $0.5 \mathrm{~Hz}$ to $20 \mathrm{kHz}$ and a sensitivity of $50 \mathrm{mV} / \mathrm{Pa}$. The geophone sensor SM4 has a frequency range from 10 to $180 \mathrm{~Hz}$ and a sensitivity of $28.8 \mathrm{~V} / \mathrm{m} / \mathrm{s}$. The geophone was therefore not able to register seismic signals with a frequency $<10 \mathrm{~Hz}$, resulting in missing data. The infrasound sensor and the geophone were placed close to the channel near the upper ultrasonic gauge for better data comparison. Furthermore, Kogelnig et al. [14] showed that this location is optimal for both infrasonic and seismic monitoring as there is minimal background noise. A Campbell Scientific CR1000 data-logger was used with a sampling rate of $100 \mathrm{~Hz}$.

A detailed description of the used signal analysis methods, such as time series analysis, running spectra, and total spectra is given by Kogelnig et al. [14, 15] and Kogelnig [16]. Figure 1 shows the infrasound and seismic data of one debris flow monitored at the Lattenbach test site on 01.09.2008. In the time series of both sensors, the arrival of the debris flow is characterized by a sudden increase in amplitudes at $650 \mathrm{~s}$ (Fig. 1a and b).

The maximum amplitudes of the infrasound signals produced by debris flows are up to $5 \mathrm{~Pa}$ and the maximum seismic amplitudes are up to $2 \times 10^{-3} \mathrm{~m} / \mathrm{s}$. As demonstrated by Kogelnig et al. [14], wave packages corresponding to four surges of the debris flow can be identified in the time series between 650 and $800 \mathrm{~s}$ (Fig. 1a and b). Both signals present a spindle shape in the time series. The total duration of the debris flow signal in the seismic and the infrasound data is $1650 \mathrm{~s}(650-2300 \mathrm{~s})$. Kogelnig et al. [14] further showed that the infrasound sensor detects the debris flow $90 \mathrm{~s}$ and the seismic sensor $50 \mathrm{~s}$ before it reaches the sensors. The total spectra (Fig. 1c and d) show that the infrasound and seismic signals are complementary. Debris flow infrasonic signals have peak frequencies from 3 to $10 \mathrm{~Hz}$, whereas seismic signals have peak frequencies from 10 to $20 \mathrm{~Hz}$. The running spectra of the debris flow (Fig. 1e and f) show a similar signal pattern in the seismic and infrasonic data. Both have a spindle shape with a rather sudden increase in frequencies and energy as the debris flow approaches the sensor location. The frequency content slowly decreases again in both sensors when the debris flow moves downstream far from the monitoring station.

\subsection{Illgraben torrent (Switzerland)}

In addition to the Austrian test site, debris flow monitoring was also performed at the Illgraben torrent (catchment area $9.5 \mathrm{~km}^{2}$ ). This is one of the most active debris flow catchments 

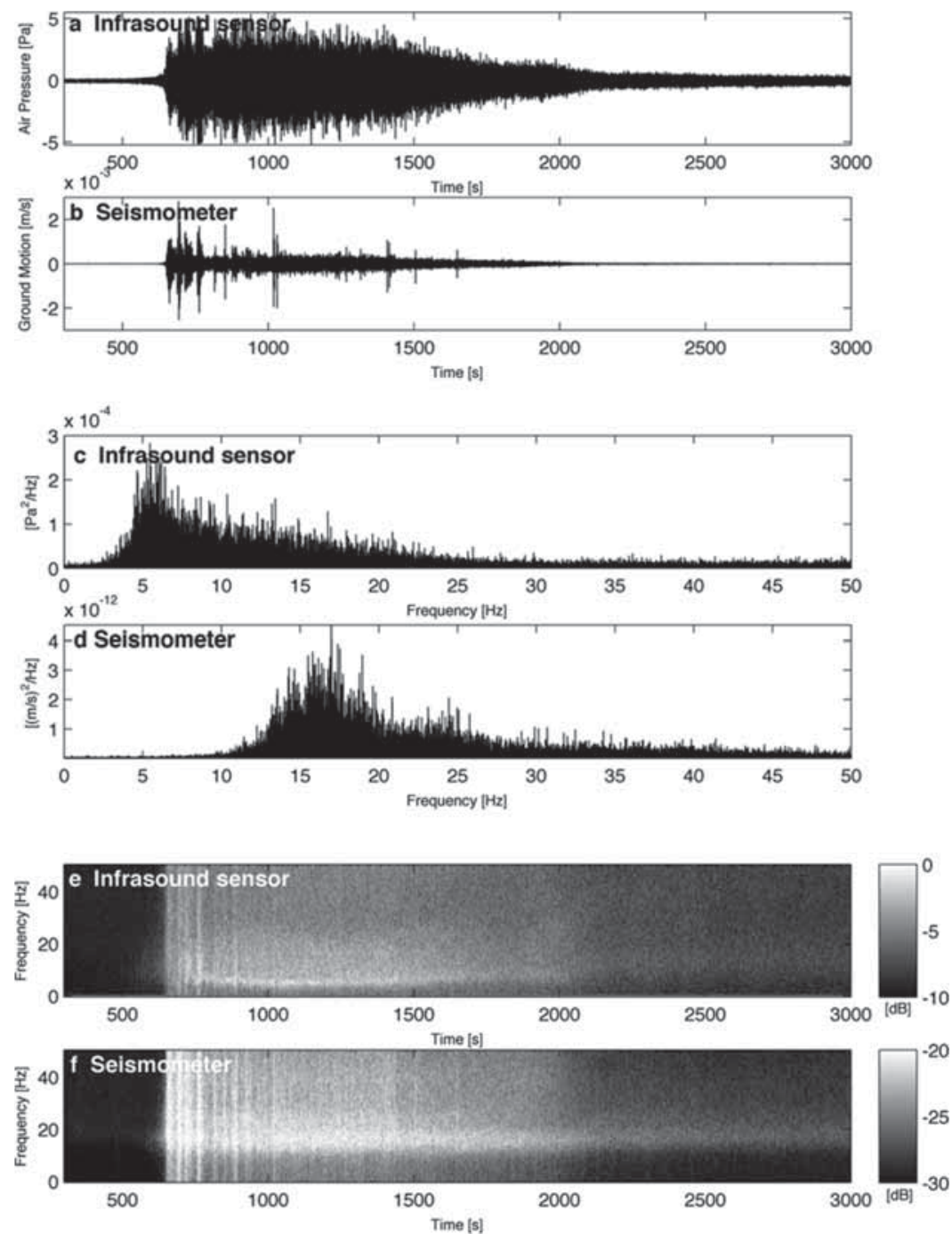

Figure 1: Infrasound and seismic (Z-component) data of a debris flow monitored at the Lattenbach test site on 01.09.2008. The signals are represented with a common base of time. (a) Infrasound time series; (b) seismogram; (c) the total spectrum of the infrasound signal; (d) the total spectrum of the seismic signal; (e) the running spectrum of the infrasound signal; and (f) the running spectrum of the seismic signal.

in the Alps, where up to seven debris flow events occur per year with a great variability of flow properties.

The Swiss Federal Institute for Forest, Snow and Landscape Research (WSL) operates the debris flow observation station at the Illgraben since 2000. In total, 29 check dams spread across the Illgraben channel. Acoustic sensors were first installed in summer 2008 at check dam 27. For a detailed overview of the test site, see [14-17]. 


\subsubsection{Acoustic data}

One infrasound capacity microphone, developed by the Acoustics Institute at the Chinese Academy of Science, with a frequency range of 3-200 Hz and a sensitivity of $50 \mathrm{mV} / \mathrm{Pa}$ was placed at check dam 27. In addition, a seismic velocimeter, model GS11, was placed near the infrasound microphone. This device has a frequency range of $4.5-100 \mathrm{~Hz}$ and a sensitivity of $90 \mathrm{~V} / \mathrm{m} / \mathrm{s}$. The data from all sensors were collected with a Campbell Scientific CR23 datalogger with a sampling rate of $100 \mathrm{~Hz}$ and were stored on an Xplore iX104 C3 tablet computer. The data of the infrasonic and seismic background noise at the Illgraben torrent have been presented by Kogelnig et al. [14]; this site generates greater background noise compared with the Lattenbach torrent, but the amplitudes are nevertheless low relative to the debris flow signal. The event discussed in the following occurred on 28.07.2009 and has already been discussed by Kogelnig et al. [15]. For the purpose of this article it is shortly summarized.

As previously explained by Kogelnig et al. [15], measurements provided by the WSL, such as bulk density $\left(\sim 1600 \mathrm{~kg} / \mathrm{m}^{3}\right)$ and flow depth from laser sensors (the flow front was small and undular), point to a debris-flood-like event; the impulse frequency of the geophone (operated by WSL, mounted in the concrete of check dam 27) indicates only weak activity at the flow front, which could indicate that there were not many boulders or just relatively small ones. Without any visual information and given the evidence mentioned above, it can be assumed that this event was a debris flood or an event that had a front like a debris flood and a body like a debris flow (private communication, Brian McArdell, WSL). Hence, we refer to this event as a debris flood (according to the classification by Hungr et al. [18]).

The infrasound and the seismic signals are presented in Fig. 2. In the time series of the infrasound sensor, several high amplitude peaks are observed in the interval $\left[1.5 \times 10^{4}-1.8 \times 10^{4} \mathrm{~s}\right]$ (Fig. 2a). Similar peaks, but with a smaller amplitude, are also observed in the seismic data in the same interval (Fig. 2b). As explained by Kogelnig et al. [15] these amplitudes correspond to the passing of a thunderstorm over the area. A smooth increase in amplitudes in the interval $\left[1.8 \times 10^{4}-1.87 \times 10^{4} \mathrm{~s}\right]$ in both sensors can be explained by a preliminary increase in discharge in the channel. In the time series of both sensors, a sharp increase in amplitudes at $1.87 \times 10^{4} \mathrm{~s}$ (Fig. 2a and b) is observed. This corresponds to the passing of the main surge of the debris flood. The maximum amplitudes of the infrasound signal in the time series produced by debris flows are up to $0.6 \mathrm{~Pa}$, and the maximum seismic amplitudes are up to $1 \times 10^{-4} \mathrm{~m} / \mathrm{s}$. After the passing of the main surge at $1.87 \times 10^{4} \mathrm{~s}$, both signals present a spindle shape in the time series of the infrasound and seismic data. The total duration of the debris flood signal in the seismic and the infrasound data is $5000 \mathrm{~s}\left[1.8 \times 10^{4}-2.3 \times 10^{4} \mathrm{~s}\right]$. Looking only at the signals in the time series, no significant difference in the debris flow event discussed in Section 2.1 can be identified.

The frequency distribution in the total spectra of the infrasound signal (Fig. 2c and d) reveals the difference. The infrasound signals have peak frequencies from 10 to $20 \mathrm{~Hz}$, whereas for the debris flow event discussed previously the peak frequencies range from 3 to $10 \mathrm{~Hz}$. These values hint that the characteristic of the process must be different. The peak frequencies in the seismic total spectrum are above $20 \mathrm{~Hz}$ (Fig. 2d), which, similar to the infrasound frequency content, is higher than that of the Lattenbach signal (seismic range 10-20 Hz).

The running spectra of the debris flood (Fig. 2e and f) show a similar signal pattern in the seismic and infrasonic data. Both have a sudden increase in frequencies and energy as the main surge of the debris flood passes the sensor location. The frequency content and the energy slowly decrease again in both sensors as the debris flood moves downstream far from the monitoring station. 

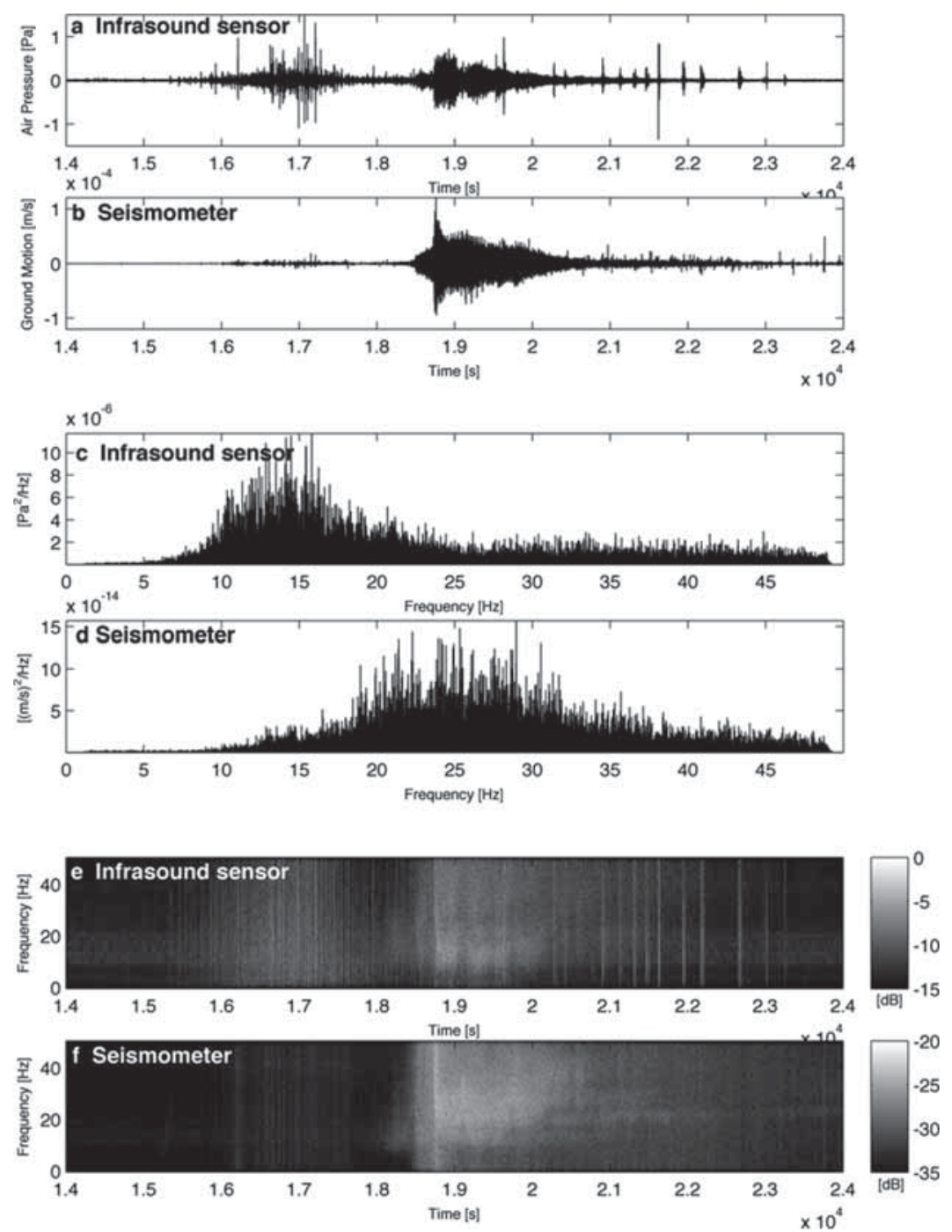

Figure 2: The infrasound and seismic (Z-component) data of a debris flood monitored at the Illgraben test site on 28.07.2009. The signals are represented with a common base of time. (a) Infrasound time series; (b) seismogram; (c) the total spectrum of the infrasound signal; (d) the total spectrum of the seismic signal; in order to show only the debris flood frequency content, a time window of $1.8-2.2 \times 10^{4} \mathrm{~s}$ was chosen for the computation of the total spectra; (e) the running spectrum of the infrasound signal; and (f) the running spectrum of the seismic signal.

\section{APPROACH FOR EARLY WARNING}

Here we describe the first version for a detection method to automatically detect the debris flow events based on seismic and infrasound data. The requirement on this detection algorithm is to identify events as early as possible without many false alarms in an uncomplex manner, so that the algorithm can be run in real time directly at the sensor site without high 
computational effort (e.g. on a microcontroller). This leads to an approach of analyzing the development of the amplitudes of the signals in a time-frequency range. The automatic detection of an event is limited by a minimal event size, weather condition, distance, and background noise.

\subsection{Detection algorithm}

The infrasound signal and the seismic signal are processed using the fast Fourier transform and analyzed with respect to time, time-frequency, and amplitude. This approach of a detection algorithm compares the development of the signal over time in three frequency bands. For the infrasound signals the three frequency bands are defined from 2 to 5,7 to 10 , and 12 to $15 \mathrm{~Hz}$; for the seismic signal the bands are defined from 7 to 10,12 to 15 , and 17 to $20 \mathrm{~Hz}$. The distribution of this frequency bands was chosen to represent the whole characteristic spectrum of debris flows, which has been already shown in Figs 1 and 2. Interfering signals are often distributed evenly over these three relevant frequency bands in contrast to debris flows, which presents a typical divergence over time at these frequency bands. Hence, the difference between the average amplitudes of these different frequency bands can be used as a detection criterion. In the current version, a mass movement is detected if the difference between these three frequency bands exceeds the limit of $1 \mathrm{mPa}$ for infrasound signals and $0.01 \mu \mathrm{m} / \mathrm{s}$ for seismic signals, for a specific time span, which is set to $15 \mathrm{~s}$. These limits and time span have been determined in an analyzing process of different debris flow and interfering signals. Only if this criterion is met by the seismic and the infrasound signals, a detection of an event is indicated, which results in a strong reduction in false alarms.

If the infrasound sensor location is much exposed to wind, an additional detection criterion can be required. Therefore, the peak frequency of the infrasound signal is used. Since the disturbances caused by the wind is usually located mainly in the range of $1-2 \mathrm{~Hz}$, the algorithm can be set to detect an event only if the peak frequency is $>2 \mathrm{~Hz}$.

This method has been tested for different debris flow signals and seems to be a promising approach. The applicability of this detection algorithm is shown below as an example of the already described events at Lattenbach torrent and Illgraben.

\subsection{Event detection: Lattenbach}

The approach for the detection algorithm has been applied to the seismic and infrasound signals of the debris flow at Lattenbach as described previously in Section 2.1. Figure 3a and $\mathrm{b}$ shows the seismic and infrasound signals of the debris flow and the diagram below depicts the average amplitudes of the respective frequency bands. The lines over the diagrams indicate the point in time of the first detection based on the particular data.

The event will be detected based on the infrasound date at $620 \mathrm{~s}$, whereas it will be detected by the seismic signal at $607 \mathrm{~s}$. Hence, at this setup the debris flow can be detected by the seismic signal $13 \mathrm{~s}$ before the algorithm, which indicates an event with the infrasound data. Based on infrasound the event will be registered for the first $30 \mathrm{~s}$ before it passes the sensor site (at $650 \mathrm{~s}$ ). The main amplitudes are in the $7-10 \mathrm{~Hz}$ frequency band at the infrasound signal and at the $17-20 \mathrm{~Hz}$ band at the seismic signal, which correlates to the data described in Section 2.1. 


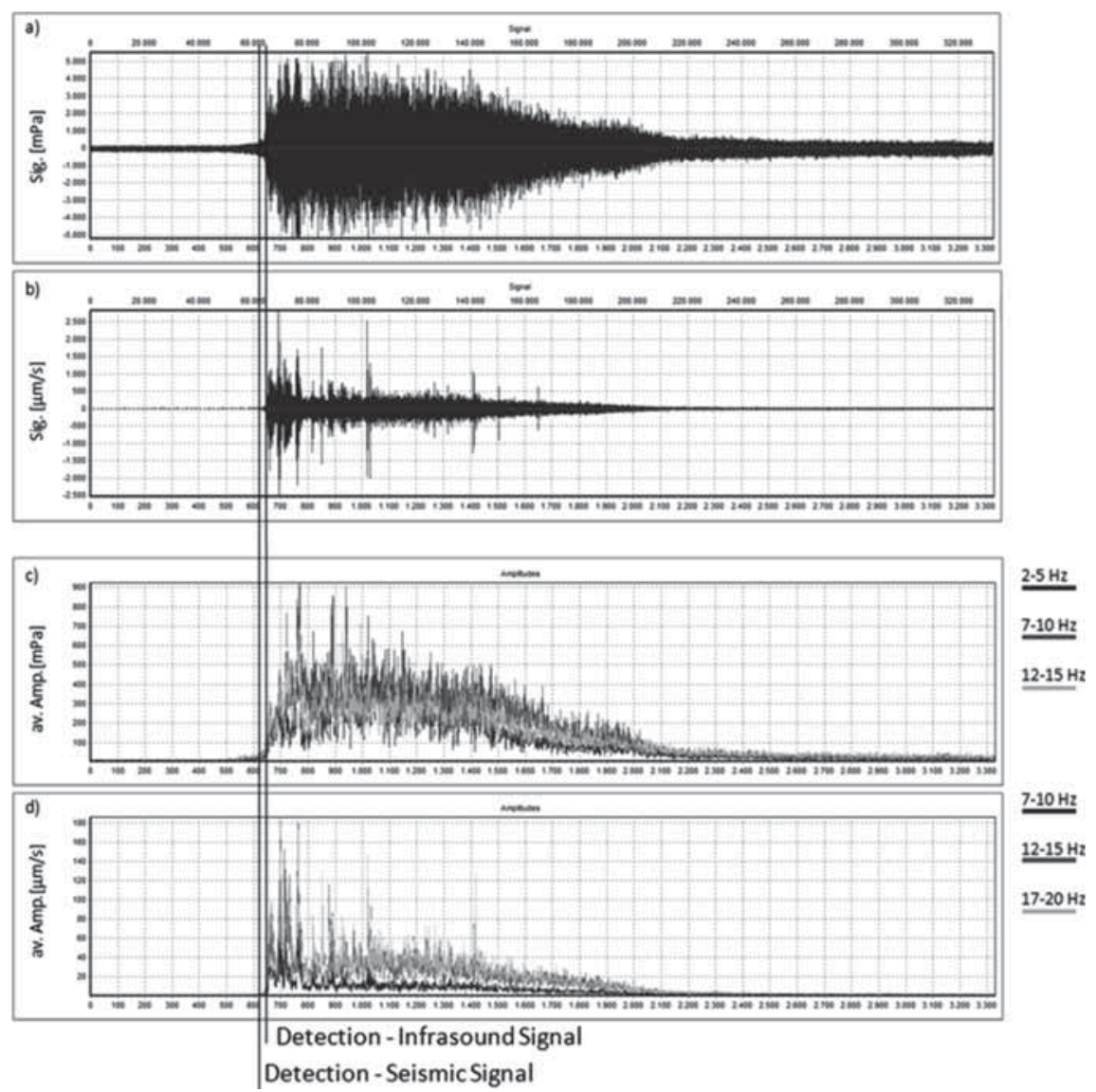

Figure 3: The infrasound and seismic (Z-component) data of a debris flow monitored at the Lattenbach test site on 01.09.2008. The signals are represented with a common base of time. (a) Infrasound time series; (b) seismogram; (c) the average amplitude of the three frequency bands of the infrasound signal; and (d) the average amplitude of the three frequency bands of the seismic signal. Lines: time of first detection based on infrasound and seismic data.

\subsection{Event detection: Illgraben}

Figure 4 shows the result of the detection algorithm applied on the seismic and infrasound signals of the debris flood event on 28.07.2009 (Section 2.2).

The detection algorithm identifies the event in the infrasound signal $3176 \mathrm{~s}$ after the start of recording, which means that the event can be detected $194 \mathrm{~s}$ before the main surge passes the sensor site (3370 s). Similar to the Lattenbach event, the detection based on the seismic signal is some time earlier at $3171 \mathrm{~s}$, which results in a registration in advance of only $5 \mathrm{~s}$. The diagram of the average amplitudes shows that the frequency band with the highest amplitude of the infrasound signal is the band from 12 to $15 \mathrm{~Hz}$, whereas the amplitudes in the $2-5 \mathrm{~Hz}$ frequency band are very low. The main amplitudes of the seismic signal are located in the 


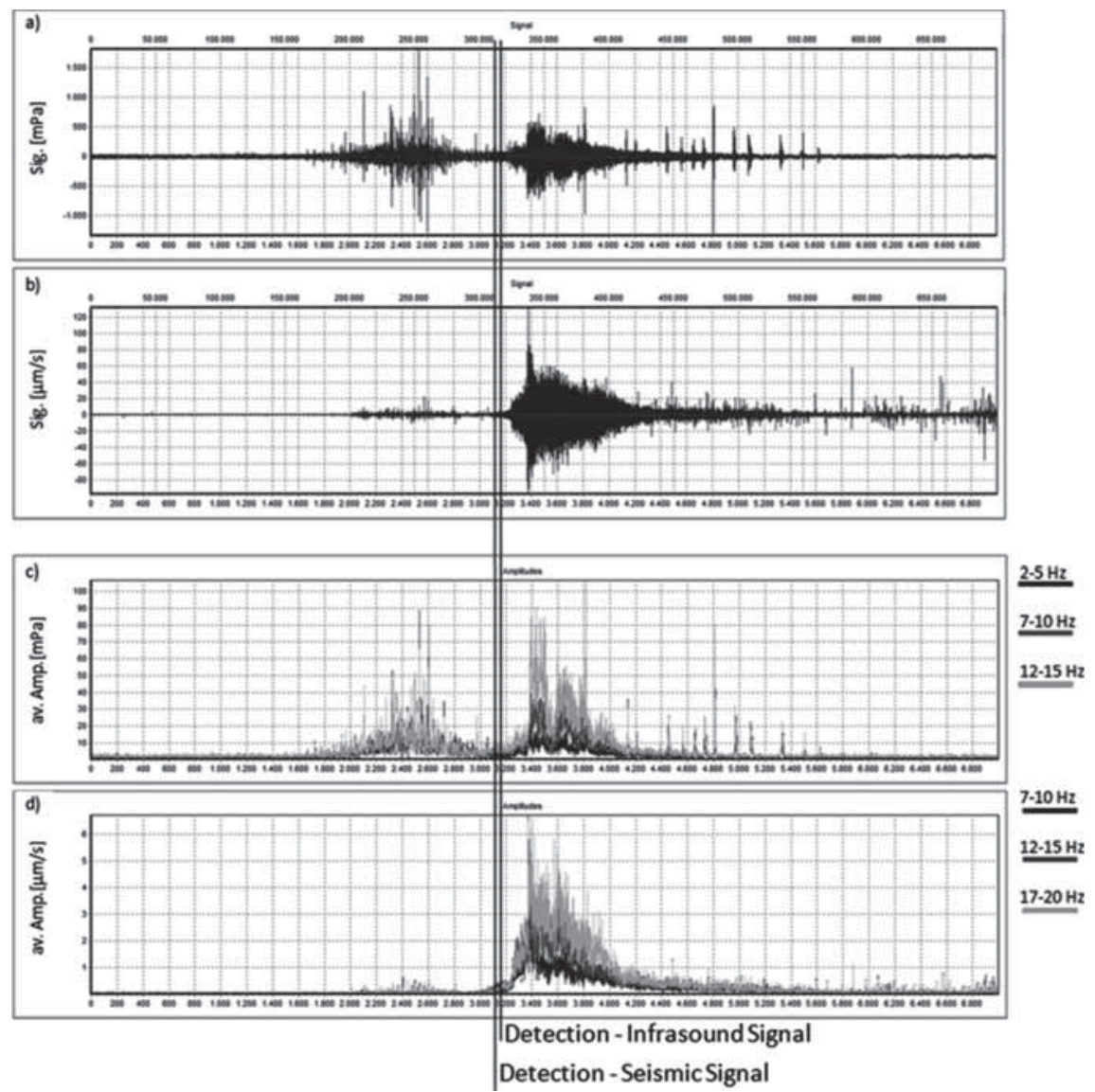

Figure 4: The infrasound and seismic (Z-component) data of a debris flood monitored at the Illgraben test site on 28.07.2009. The signals are represented with a common base of time. (a) Infrasound time series; (b) seismogram; (c) the average amplitude of the three frequency bands of the infrasound signal; and (d) the average amplitude of the three frequency bands of the seismic signal. Lines: time of first detection based on infrasound and seismic data.

17-20 Hz band, which complies with the peak frequencies described previously in Section 2.2. The comparison of the results of the detection algorithm for the events at Lattenbach and Illgraben shows significant differences between the detection times based on seismic or infrasound data depending on the signal sequence and local conditions, and a wide variance of the early warning times.

\section{CONCLUSIONS}

This article presents a review on acoustic monitoring of debris flows based on previous studies conducted by Hübl et al. [19], Kogelnig et al. [14, 15], and Kogelnig [16]. It analyses the application of infrasound and seismic sensors for monitoring and characterization of debris flows and presents an approach for early warning based on these signals. For the first time, in-depth studies combining the infrasound and seismic wave fields generated by alpine 
mass movements have been carried out. We showed that the combination of infrasound and seismic sensors is a valuable tool for monitoring debris flows and automatic event detection and that (i) infrasound and seismic signals are correlated with each other and also with other measurements (e.g. flow depth for debris flows) and (ii) the combination of both sensor technologies increases the detection probability and minimizes false alarms. Hence, with these complementary technologies it will be possible to build up a reliable warning system, which comes along with only one seismic and one infrasound sensor (co-located) instead of using multiple spatially distributed sensors (arrays), and are the basis of the most current detection systems (e.g. [11]).

However, the application of seismic and infrasound sensors for monitoring and detection of alpine mass movements is not a straightforward task. Thorough investigations of the study site and the background noise characteristics are necessary to determine the suitability for acoustic monitoring. Understanding the propagation and attenuation mechanisms of seismic and infrasonic waves in the study conditions is crucial for the interpretation of the recorded seismic and infrasonic signals. The equipment and the placement of the sensors have to be chosen carefully, as shown by the results obtained in China (see [15]).

Previous studies $[14-16,19]$ recorded infrasound and seismic data of several torrential processes (debris flows and debris floods) in Switzerland and Austria. In addition, numerous sources of interfering signals were studied and discussed by Kogelnig [16]. The detailed analysis of all the seismic and infrasonic signals allowed not only to find a characteristic evolution in the time and frequency domain for the specific processes studied but also to make a clear differentiation from interfering signals. The studies confirmed that debris flows produce seismic and infrasonic signal characteristics that are reproducible at very different experimental sites and under different environmental conditions.

Table 1 summarizes the main characteristics of infrasound and seismic data of debris flows and debris flood in view of the other common sources of infrasound signals, which have been presented by Kogelnig [16] and gives an overview of the achieved detection times with the introduce detection algorithm.

Table 1: The summary of the recorded maximum amplitudes (MA) of the seismic signals $(\mathrm{m} / \mathrm{s})$ and infrasound signals $(\mathrm{Pa})$ of debris flow and debris flood. Also summarized are the total duration (s) based on the seismic and infrasound data, the peak frequency content $(\mathrm{Hz})$, the time of automatic detection before peak amplitude (s), and the typical pattern in the running spectra (RS).

\begin{tabular}{lcc}
\hline & Lattenbach & Illgraben \\
& Debris flows & Debris flood \\
\hline MA $_{\text {IS }}$ & $4.8 \mathrm{~Pa}$ & $0.6 \mathrm{~Pa}$ \\
MA $_{\text {SEIS }}$ & $2 \times 10^{-3} \mathrm{~m} / \mathrm{s}$ & $1 \times 10^{-4} \mathrm{~m} / \mathrm{s}$ \\
Total duration & $1650 \mathrm{~s}$ & $5000 \mathrm{~s}$ \\
Peak freq. IS & $3-10 \mathrm{~Hz}$ & $10-20 \mathrm{~Hz}$ \\
Peak Freq. SEIS & $10-20 \mathrm{~Hz}$ & $>20 \mathrm{~Hz}$ \\
Detection time IS & $30 \mathrm{~s}$ & $194 \mathrm{~s}$ \\
Detection time SEIS & $43 \mathrm{~s}$ & $199 \mathrm{~s}$ \\
Pattern in RS & Spindle shape & Spindle shape \\
Pattern in RS $_{\text {SEIS }}$ & Spindle shape & Spindle shape \\
\hline
\end{tabular}


Besides the purpose of detection, seismic and infrasonic signals were used to determine relevant physical information related to the dynamics of the process.

For torrential processes it has been shown that the frequency content of the infrasound signals varies between debris flows and debris floods. Debris flows generally have lower peak frequencies in the infrasound signal $(\sim 5 \mathrm{~Hz})$ compared with debris floods $(>7 \mathrm{~Hz})$. The amplitude and frequency contents of the seismic and infrasound signals increase as the debris flow moves toward the sensors. During the passage of the debris flow, the ultrasonic gauges identified several surges. The time series and the running spectra of the seismic and infrasonic data also recognize these surges. The relative detection capabilities of both sensors are strongly dependent on the terrain. At the Lattenbach torrent the infrasound sensor detects the debris flow before the seismic sensor, whereas at the Illgraben the opposite was observed [14]. We believe that high mountain ridges, as is the case at the Illgraben, produce a natural sound barrier with an acoustic shadow zone behind. If the infrasound sensor is placed within this shadow zone, the forecast time is significantly reduced. Seismic sensors provide signals in near real time owing to the high seismic speed in the ground, but they are more sensitive to signal attenuation effects, strongly depending on the characteristics of the ground and the distance between the source and the receiver. However, the observed signals are too small at the beginning for an automatic detection; hence, with the application of the detection algorithm, this difference cannot be observed and the detection algorithm based on seismic data always register the event a few seconds earlier than that based on the infrasound data.

In summary, the initial motivation for this study, i.e. to investigate for the first time a combination of infrasound and seismic sensors for monitoring alpine mass movements and use these signals for an automatic detection, showed promising results. The combined analysis of the emitted infrasonic and seismic wave field gives further insights into the process monitored.

\section{REFERENCES}

[1] Okuda, S., Okunishi, K. \& Suwa, H., Observation of debris flow at Kamikamihori Valley of Mt. Yakedade, Excursion Guide-book of the Third Meeting of IGU commission on Field Experiment in Geomorphology, Japanese geomorphological union, pp. 127-130, 1980.

[2] Wu, J., Kang, Z., Tian, L. \& Zhang, S., Observation and investigation of debris flows at Jiangjia Gully in Yunnan Province (China), Science Press: Beijing, China, 1990.

[3] Hadley, K. \& Lahusen R., Deployment of an acoustic flow monitor system and examples of its application at Mount Pinatubo, Philippines (abstract), Eos Trans, AGU, 72(44), F67, 1991.

[4] Marchi L., Arattano M. \& Deganutti, A., Ten years of debris-flow monitoring in the Moscardo Torrent (Italian Alps). Geomorphology, 46(1-2), pp. 1-17, 2002. doi: http:// dx.doi.org/10.1016/S0169-555X(01)00162-3

[5] Arattano, M., On the use of seismic detectors as monitoring and warning systems for debris flows. Natural Hazards and Earth System Sciences, 20, pp. 197-213, 1999.

[6] Huang, C., Yin, H. \& Shieh, C., Experimental study of the underground sound generated by debris flow. Proc. of the 3rd Int. Conf. on Debris-Flow Hazards Mitigation: Mechanics, Prediction and Assessment, Millpress: Rotterdam, 2, pp. 731-743, 2003.

[7] Huang, C., Yin, H., Chen, C., Yeh, C. \& Wang C., Ground Vibrations produced by rock motions and debris flow. Journal of Geophysical Research, 112, F02014, 2007. doi: http://dx.doi.org/10.1029/2005JF000437 
[8] Adam, V., Chritin, V., Rossi, M. \& Bolognesi, R., Acoustic detection system for operational avalanche forecasting. Proc. of the International Snow Science Workshop, Banff, Alberta, pp. 149-153, 1997.

[9] Zhang, S., Hong, Y. \& Yu, B., Detecting infrasound emission of debris flow for warning purposes. International Symposium Interpraevent VII, Riva, Trient, pp. 359-364, 2004.

[10] Chou, H., Cheung, Y. \& Zhang, S., Calibration of infrasound monitoring system and acoustic characteristics of debris-flow movement by field studies. Debris-flow Hazards Mitigation: Mechanics, Prediction, and Assessment, eds. C. Chenglung \& J. Major, Millpress: Rotterdam, pp. 571-580, 2007.

[11] Scott, E., Hayward, C., Kubichek, R., Hamann, J., Comey, R., Pierre, J. \& Mendenhall, T., Single and multiple sensor identification of avalanche generated infrasound. Cold Regions Science and Technology, 47, pp. 159-170, 2007. doi: http://dx.doi.org/10.1016/ j.coldregions.2006.08.005

[12] Arrowsmith, S., Johnson, J., Drob, D. \& Hedlin M., The seismoacoustic wavefield: a new paradigm in studying geophysical phenomena. Reviews of Geophysics, 48, RG4003, 2010. doi: http://dx.doi.org/10.1029/2010RG000335

[13] Hübl, J. \& Moser, M., Risk management in Lattenbach: a case study from Austria. Monitoring, Simulation, Prevention and Remediation of Dense and Debris Flows, eds. G. Lorenzi, C. Brebbia \& D. Emmanouloudis, WIT Press: Southamption, pp. 333-342, 2006. doi: http://dx.doi.org/10.2495/DEB060321

[14] Kogelnig, A., Hübl, J., Suriñach, E., Vilajosana, I. \& McArdell, B., Infrasound produced by debris flow: Propagation and frequency content evolution. Natural Hazards, doi: http://dx.doi.org/10.1007/s11069-011-9741-8.

[15] Kogelnig, A., Hübl, J., Suriñach, E., Vilajosana, I., Zhang, S., Yun, N. \& McArdell, B., A study of infrasonic signals of debris flows. Italian Journal of Engineering Geology and Environment - Book, eds. R. Genevois, D. Hamilton \& A. Prestininzi, pp. 563-572, ISBN: 1825-6635; ISSN 978-88-95814-46-9, 2011.

[16] Kogelnig, A., Development of Acoustic Monitoring for Alpine Mass Movements, PhD Thesis, University of Natural Resources and Life Sciences (BOKU), Vienna, Institute of Mountain Risk Engineering, 2012.

[17] Graf, C., Badoux, A., McArdell, B., Dufour, F., Rhyner, J. \& Kuntner, R., A Warning System for Natural Hazards in Summer at the Illgraben, 4th Swiss Geoscience Meeting: Bern, 2006.

[18] Hungr, O., Evans, S., Bovis, M. \& Hutchinson, J., A review of the classification of landslides of the flow type. Environmental and Engineering Geoscience, 7(3), pp. 221-238, doi: 10.2113/gseegeosci.7.3.22, 2001.

[19] Hübl, J., Zhang, S. \& Kogelnig, A., Infrasound measurements of debris flow. WIT Transactions on Engineering Sciences, Second International Conference on Monitoring, Simulation, Prevention and Remediation of Dense and Debris Flows II, eds. D. De Wrachien, C.A. Brebbia \& M.A. Lenzi, 60, pp. 3-12, ISSN 1743-3533, 2008. doi: http://dx.doi.org/10.2495/DEB080011

"This is a revised version of the paper published in WIT Transactions on Engineering Sciences, Vol 73, (C) 2012 WIT Press, www.witpress.com, ISSN 1743-3533 (on-line), doi: 10.2495/ DEB120071." 